\title{
Engineering Material Selection for Automotive Exhaust Systems Using CES Software
}

\author{
Ikpe Aniekan E. ${ }^{*}$, Orhorhoro Ejiroghene Kelly ${ }^{* *}$, Gobir Abdulsamad $^{*}$ \\ *Department of Mechanical Engineering Coventry University, Priory Street, CV15FB, West Midlands, UK \\ ${ }^{* *}$ Cemek Machinery Company Technology Incubation Centre, Federal Ministry of Science \& Technology \\ Benin City, Edo State, Nigeria \\ (ikpeaniekan@gmail.com, kelecom@yahoo.com, abdulsamad.gobir@gmail.com)
}

*Corresponding Author: Ikpe Aniekan, Swan court Flat 11, Coventry, CV24NR. Tel: +447586821646, ikpeaniekan@gmail.com

Received: 32.12.2016 Accepted: 05.06.2017

\begin{abstract}
This report reviews the automotive exhaust system with respect to its in-service conditions and selection of suitable materials for exhaust manifold, downpipe silencer/ muffler box and tail pipe which comprises the exhaust system. The functions of each component were discussed, highlighting how they function as part of the exhaust and Cambridge Engineering Software (CES) software was employed in the material selection process. Mass, cost, high temperature $\left(>800^{\circ} \mathrm{C}\right.$ for exhaust manifold and $>400^{\circ} \mathrm{C}$ for downpipe silencer/ muffler box and tail pipe) and high corrosion resistance were used as basic criteria for the material selection. Variety of materials including Nickel-based superalloys, stainless steel, Nickelchromium alloys were obtained in the material selection route for exhaust manifold. Similarly, low alloy steels, stainless steel, grey cast iron, Nickel-based superalloys, Nickel-chromium alloys were obtained in the material selection for downpipe silencer/ muffler box and tail pipe. Nickel-based superalloys and Nickel-chromium alloys possess suitable properties for this application, but were not considered due to their high densities and high cost. Low allow steels were not selected because they tends to exhibits poor corrosion resistance when exposed to salt on the road surface and condensate from the exhaust system. Grey cast iron has low tensile strength and elongation and therefore not exhibit enough toughness required to withstand the severe working conditions. However, stainless steel (Ferritic stainless steel and Austenitic stainless steel) was considered as a better choice of material for automotive exhaust systems due to its considerable price and density, acceptable strength at elevated temperatures and excellent corrosion resistant it possesses as a result of the protective film of chromium oxide which forms on the surface of the metal.
\end{abstract}

Keywords Material, Cost, Exhaust system, Temperature, Corrosion, Mass, Service life.

\section{Introduction}

Automobile exhaust systems are integral parts of the overall chain of functions in an automotive system. The significance of exhaust systems has evolved to cover various functional processes in an automobile. Owing to this revolution, material selection prior to manufacturing of automotive exhaust systems has been very crucial. A typical automotive exhaust system incorporates piping system that directs hot reaction gases away from the combustion chamber of an internal combustion engine of automobile systems [10]. In other words, the exhaust system which comprises one or more exhaust pipes conveys burnt toxic and noxious gases through one or more exhaust pipes away from the engine, and depending on the exhaust design, the burnt gases may be expelled through the Catalytic converter to minimise air pollution, resonator, tailpipe etc.

In principle, the exhaust pipes connects the exhaust manifold, resonator, muffler and catalytic converters together for effective exhaust flow, minimal noise, and emission levels. Exhaust systems operate at relatively high temperature and such operating condition usually necessitate the use of materials with high resistance to heat property, in order to prevent thermal corrosion from limiting the service life of the exhaust material. Furthermore, due to the effects of $\mathrm{CO}_{2}$ emissions on the environment, Green House Gas (GHG) emission taxes incurred by automobile manufacturers and the ongoing fight against reduction of GHG emissions by United Nations and by IPCC and other environmental protection agencies, manufactures in recent times have conducted researches on possible ways of ensuring that emission of toxic and/or noxious gases into the environment is minimised and the use of suitable materials is one of such [16]. To this revolution, material selection during manufacturing process of automobile exhaust system has been very important. Initially, combustion systems were used to reduce noises produced by high-pressure exhaust gases that were emitted in large amounts by first generation automobiles [5].

The evolution of functioning systems in automobile exhaust, advances in technology and material science have made tremendous significance in the production of the best materials and designs for automobile exhaust systems. As regards material selection and design, there are many factors that must be put into consideration [3, 6]. Illustration by 
Precision Automobile [14] shows that a typical automotive exhaust system is made up of the exhaust manifold, a flexible joint, a catalytic converter, a muffler box, tail pipe etc. as shown in Fig. 1. Each of these sections has distinct functions that are significant in the operational gymnastics of the automobile exhaust system [2].

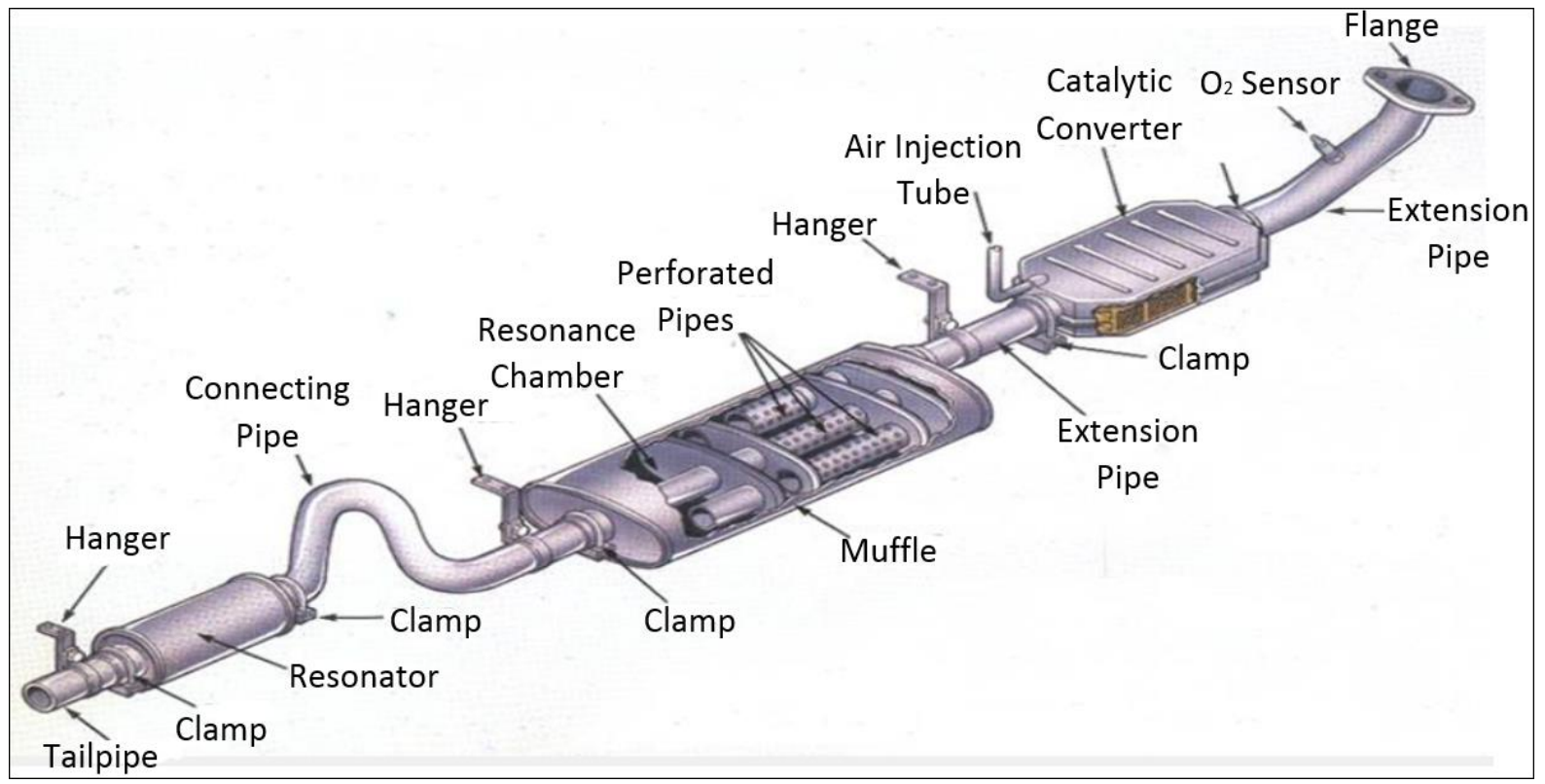

Fig. 1. Typical view of an Automotive Exhaust System [14].

\subsection{Exhaust Manifold}

The Exhaust manifold are units of pipes made of special material that collect exhaust gases from the engine outlets (through valves) and channel them into a common exhaust pipe. The nature and appearance of the exhaust manifolds depend largely on not only the engine but also the nature of the exhaust materials to be transported. Studies in thermodynamics provide the exact operational temperatures for each conversion in the engine that helps in the determination of important parameters that aid in material selection [6].

The exhaust manifold is installed adjacently to the engine part where the exhaust outlet is situated. At the end of the exhaust stroke of a normal automobile engine, the exhaust valve opens, and the exhaust gas that was filled in the cylinder escapes at high pressure into the exhaust manifold.

As a result of the pressure and the velocity in which the exhaust gases are emitted by the engine through the exhaust valve, the exhaust materials gas possess high temperatures [13]. However, as the exhaust materials are transported through the exhaust manifold, divergent pressure reduction and equalization activities happen that not only reduces the pressure content, but also the velocity of the gases. Therefore, material selection for the exhaust manifold of the automobile exhaust system should incorporate the consideration of all these factors. Essentially, the material should be able to withstand the high pressures exhibited by the exhaust gases as they are thrust out through the exhaust valve. Also, the nature of the gases emitted by each engine is largely dependent on the fuel the engine operates on.

Fundamentally, there are diesel and petrol engines, each of which emits different types (by composition) of exhaust gases. Therefore, the material chosen should not react with any chemical component in the exhaust mixture. This is because reactions between the material and the exhaust gases will not only corrode the exhaust manifold, but also reduce its durability drastically. Moreover, the operating temperature $\left(700-800^{\circ} \mathrm{C}\right)$ of the exhaust gases should also be a guiding factor in the selection of the most appropriate material. Logically, each engineering material has a unique thresh-hold temperature point above which the qualities of the material are affected. During operation, exhaust materials can be exposed to ambient temperature level up to $800^{\circ} \mathrm{C}$ or even higher under certain severe conditions.

The exhaust system during operation is also exposed to a number of various chemical conditions such as road salt, alkaline and acidic exhaust condensate within the exhaust system. Based on these factors, materials selected for manufacturing of exhaust system must possess not only sufficient strength and fatigue resistance but also excellent corrosion resistance against varieties of operational conditions.

While metals generally form a protective oxide layer on the surface, variety of mechanisms can affect this oxide layer and gradually expose the metal substrate to degradation. Some failure mechanisms that can easily hamper the service life of exhaust system material during its in-service condition as follows;

\footnotetext{
i. High temperature corrosion (dry hot corrosion)

ii. Condensate and salt corrosion (wet corrosion)

iii. Elevated temperature mechanical failure

iv. Stress corrosion cracking

v. Intergranular corrosion
} 


\section{2. Muffler Box}

The muffler box is positioned in between the centre pipe and the tail pipe. It functions as a damper of exhaust noise by suppressing it to an acceptable level before passing out to the environment through the last outlet called the tail pipe which is visible to the human eye in an automotive. The internal combustion engines generate high intensity pressure waves which are propagated along the engine exhaust parts.

Fundamentally, the noise produced inside the engine is transported in the form of pulses. Therefore, the main function of the muffler box is to suppress these pulses and reduce them to a frequency that would not cause exorbitant pollution to the environment. Additionally, these pulses can cause vibrations that could be transmitted to other parts of the automobile [12]. Therefore, the material selected should incorporate a sound absorbing material that is within the range of the sounds propagated from the specific engine that it is used. Given that sound is transmitted in a form of pulses and waves. As a matter of fact, mufflers used in modern vehicles use reactive silencers that reflect the propagated sounds back to the sources and inhibit their propagation (in the original frequencies) to the environment through the tail pipe.

Technically, the muffler box has important aspects that tie it with the tail pipe; a choice of the material for design for the muffler box directly affects the choice of materials for the tail pipe. The muffler box is structured in a way that it should not have anything in its interior that would interrupt the flow of exhaust gases.

\section{3. Tail Pipe}

The tail pipe is coupled with the muffler box and lies adjacently to the tail of the muffler box. The main function of the tail pipe is to relay sound and excessive exhaust gases from the automobile exhaust system. This is virtually the end part of the whole exhaustive system.

\section{Loading Conditions}

The mechanical loading condition in which an automotive exhaust system operates under are highlighted as follows;

\subsection{Thermal Loading}

This arises due to uneven expansion of some areas on the exhaust pipes especially when the material is exposed to high temperature. This uneven expansion can initiate crack or can superimposed on existing crack to extend the crack length [15].

The thermal stress is given by

$\sigma_{T}=E \alpha\left(T_{2}-T_{1}\right)$

Where

$\sigma_{T}$ is the stresses due to uneven expansion

$E$ is the Young's Modulus of the material

$\alpha$ is the coefficient of thermal expansion

$\left(T_{2}-T_{1}\right)$ is the temperature gradient.

Material Characteristics for the major components in a typical vehicle exhaust are presented in Table 1.

Table 1. Material Characteristics for Vehicle exhaust system Components [10]

\begin{tabular}{|l|l|c|c|}
\hline \multicolumn{1}{|c|}{ Criteria } & Exhaust Manifold & Muffler Box & Tail Pipe \\
\hline $\begin{array}{c}\text { Service } \\
\text { Remperature }\end{array}$ & $750-900^{\circ} \mathrm{C}$ & $100-400^{\circ} \mathrm{C}$ & $100-400^{\circ} \mathrm{C}$ \\
\hline Properties & $\begin{array}{l}\text { - Resistance to High } \\
\text { temperature } \\
\text { - Thermal Fatigue life } \\
\text { - Oxidation resistance }\end{array}$ & $\begin{array}{l}\text { - Corrosion resistance } \\
\text { - Oxidation resistance }\end{array}$ & $\begin{array}{c}\text { - Corrosion resistance } \\
\text { - Oxidation resistance }\end{array}$ \\
\hline
\end{tabular}

\subsection{Residual Stress}

The residual stress is incduces due to vibration on the exhaust system as a result of loading condition when the car is in operation. If these vibrations are close to the natural frequency of the material, resonance may occur. Such high vibration frequency can initiate crack.

\subsection{Fracture Toughness (Klc)}

The position of the exhaust system exposes its parts to frequent vibrations and knockings that usually result in crack initiation over time. Therefore, it is important to look inward for materials that possess high fracture toughness to resist crack propagation from existing cracks and to reduce the effect of residual stresses caused by vibrations and other loading effects. Material index to optimise fracture toughness and resistance to Stress Corrosion Cracking (SCC) for the exhaust system components [11] is given as
$\mathrm{K}_{1 \mathrm{c}}=\sigma(\pi c)^{0.5}$

Where

$\mathrm{K} 1 \mathrm{c}$ is the fracture toughness

$\sigma$ is the stress distribution and

$\mathrm{c}$ is a very small crack.

$$
\begin{aligned}
& \mathrm{K}_{1 \mathrm{c}}=\frac{w l}{A}(\pi c)^{0.5} \\
& A=\frac{w l}{\mathrm{~K}_{1 \mathrm{c}}}(\pi c)^{0.5} \\
& m_{3}=\frac{w l}{\mathrm{~K}_{1 \mathrm{c}}}(\pi c)^{0.5} l \rho \\
& m_{3}=w l^{2}(\pi c)^{0.5}\left(\frac{\rho}{\mathrm{K}_{1 \mathrm{c}}}\right)
\end{aligned}
$$

In order to optimize performance indices $m_{3}=m_{1}$ To minimize mass, $\frac{\mathrm{K}_{1 \mathrm{c}}}{\rho}$ should also be maximized. 


\section{Methodology}

Material selection is a very important part of engineering processes as far as the design of systems is concerned. Generally, effective material selection process implies selecting materials with optimal costs with good performance that meets the component designed service life. Based on the above material requirements and materials indices, a search was carried out using the Cambridge Engineering Selector (CES) software Level 3 to select suitable materials for automotive exhaust manifold. Since the service temperature considered for a typical automotive exhaust system is about $800^{\circ} \mathrm{C}$ and above, a minimum temperature of $800^{\circ} \mathrm{C}$ was set to filter off materials whose service temperature is below this value.

Moreover, fracture toughness is one of the most important factors that determine the longevity of the exhaust system under such severe condition. Therefore, a minimum value of $15 \mathrm{Mpa} . \mathrm{m}^{0.5}$ was used to filter off materials with fracture toughness below this value. Similarly for muffler box and tail pipe, a minimum service temperature of $400^{\circ} \mathrm{C}$ and fracture toughness $>15 \mathrm{Mpa} \cdot \mathrm{m}^{\wedge} 0.5$ were used in the material selection process. Applying the above parameters in each material selection process generated the following graphs. The objective of the material selection process is to minimise cost, maximize Thermal Strength and minimise Mass.
Materials selected at the end of each process must possess certain characteristics that meets the following criteria;

i. High Melting point due to high temperature gases passing through the exhaust system. High Service temperature above $800^{\circ} \mathrm{C}$ for exhaust manifold and above $400^{\circ} \mathrm{C}$ for Muffle box and tailpipe.

ii. High resistance to corrosion. Internal and externaldifferent environments specify

iii. Oxidation considering hot water vapour of exhaust gas.

iv. Low density which can improve fuel economy.

v. High young modulus in order to withstand vibration from the engine.

vi. High thermal conductivity in order to allow even spreading of heat along the whole component.

vii. High fracture toughness to resist crack propagation from an existing crack.

viii. High resistance to thermal fatigue considering high temperature of above $800^{\circ} \mathrm{C}$ for exhaust manifold and above $400^{\circ} \mathrm{C}$ for Muffle box and tailpipe.

ix. High yield strength to withstand the thermal stresses.

Fig. 2 presents the criteria for limits applied in the material selection for the Exhaust Manifold.

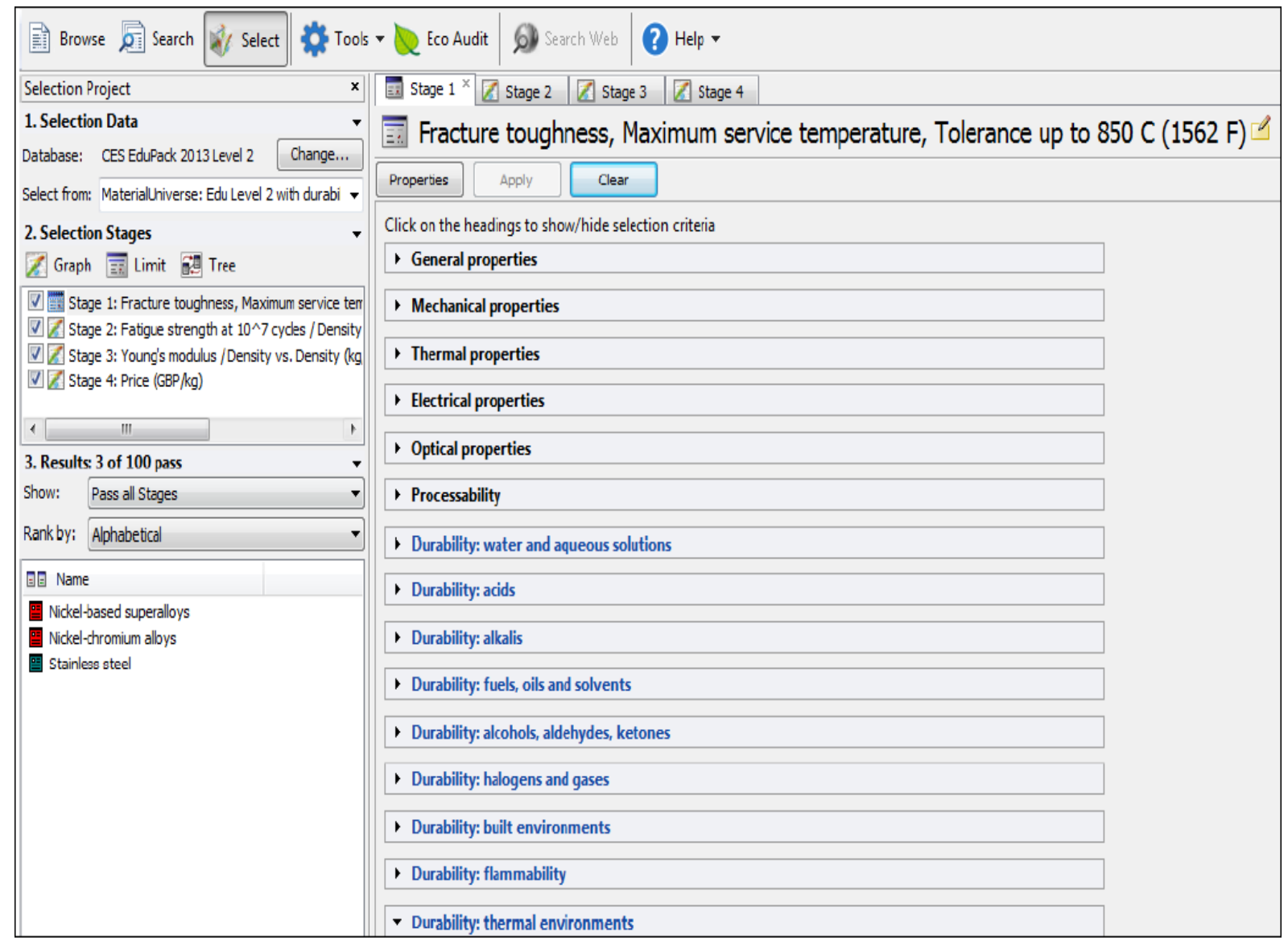

Fig. 2. Chart of Limits Applied in Material Selection for Exhaust Manifold. 


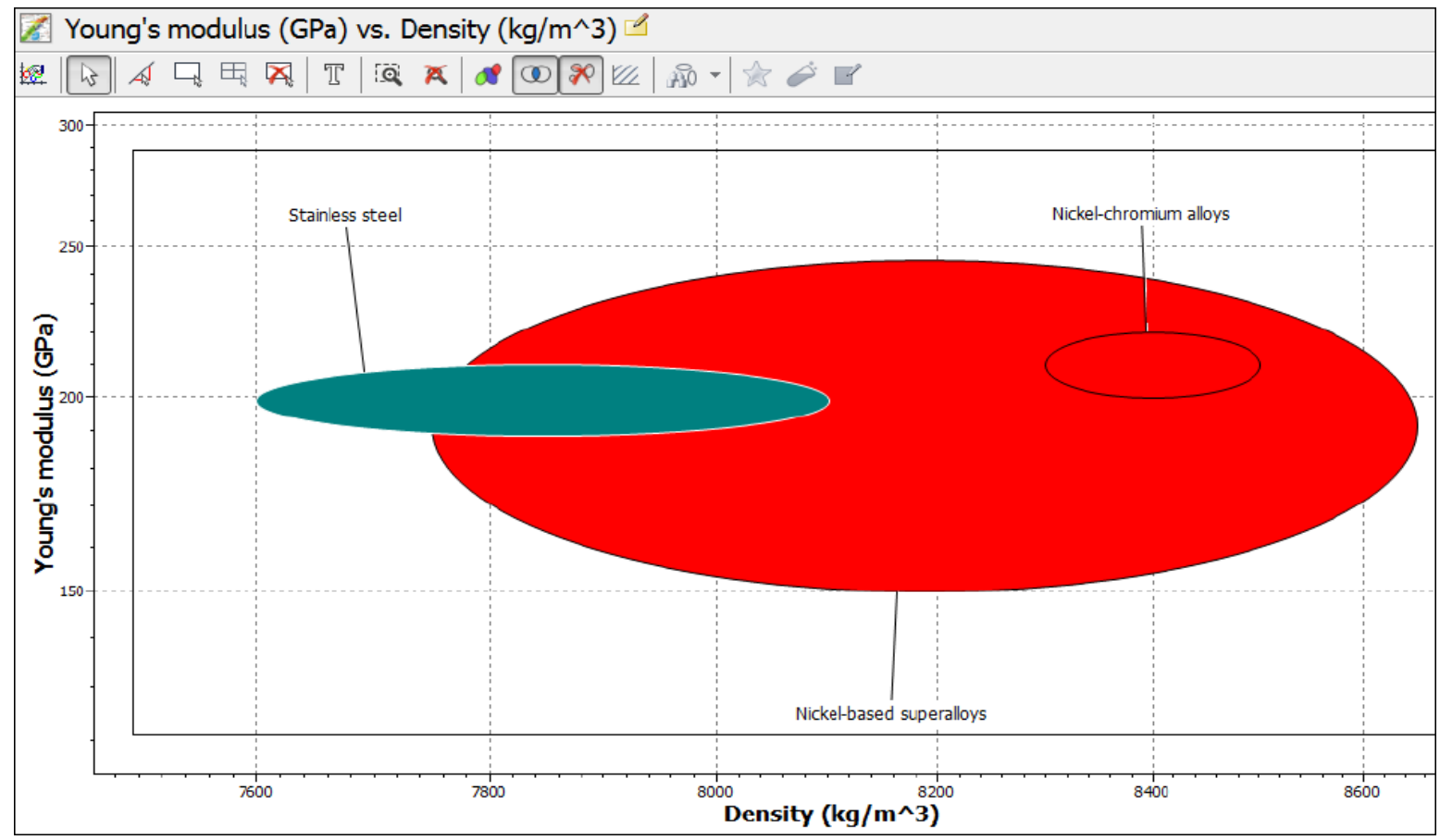

Fig. 3. Graph of Specific Young's Modulus (GPa) against Density $\left(\mathrm{kgm}^{-3}\right)$.

The graph above demonstrates the materials young's modulus (GPa) against density (kg-3). The material shown in Fig. 3, stainless steel, nickel-chromium alloys and nickelbased alloys have high young modulus which provides the required stiffness but stainless steel has a moderately low density which makes it a better choice of material for automotive exhaust than nickel. Fig. 4 represents a Graph of Fatigue strength at $10^{\wedge} 7$ cycles/Density $\left(\mathrm{kgm}^{-3}\right)$ plotted against Thermal expansion coefficient ( $\mu$ strain $/{ }^{\circ} \mathrm{C}$ ).

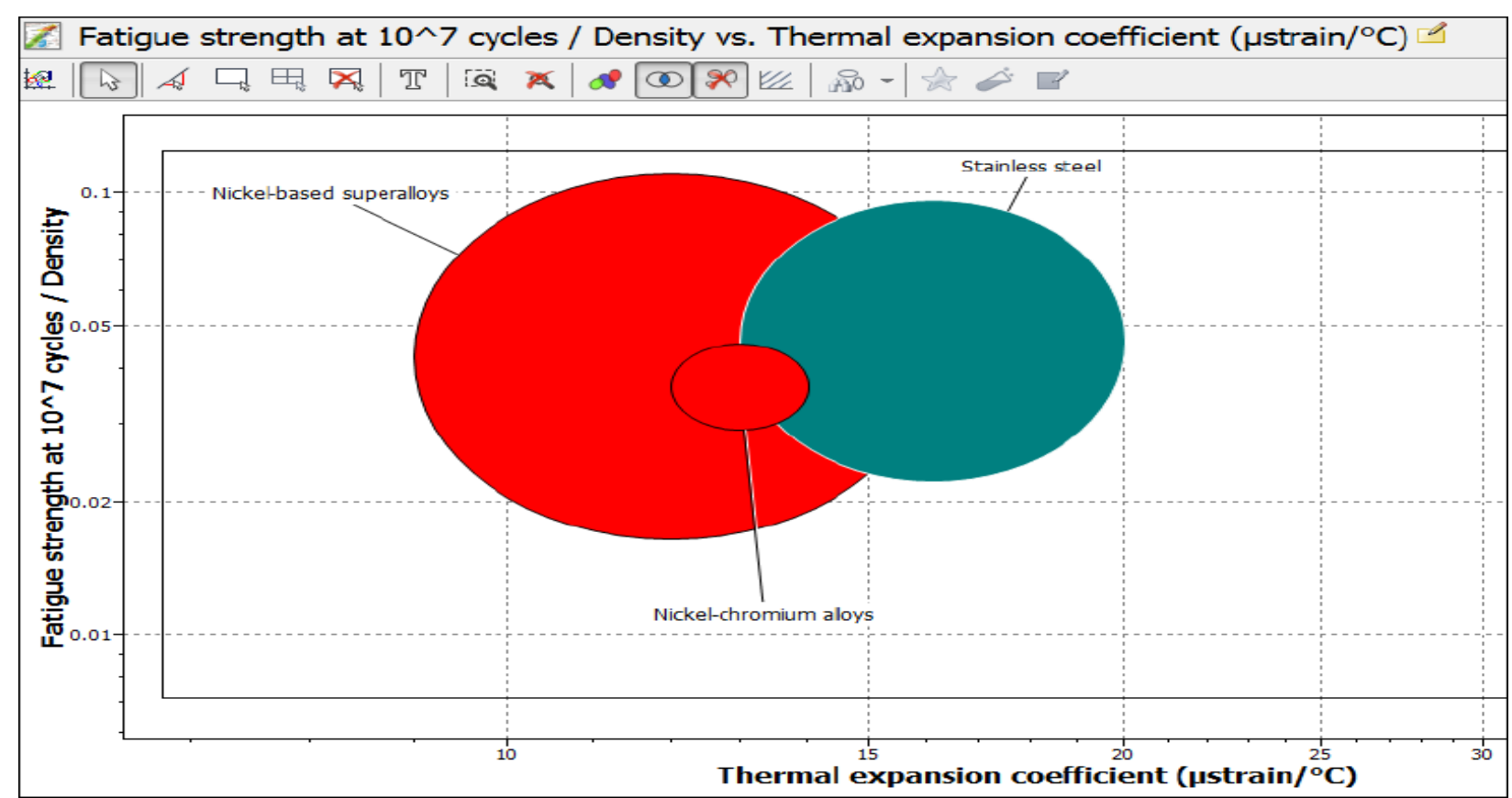

Fig. 4. Graph of Fatigue strength at $10^{\wedge} 7$ Density $\left(\mathrm{kgm}^{-3}\right)$ against Thermal Expansion Coefficient $\left(\mu \mathrm{strain} /{ }^{\circ} \mathrm{C}\right)$.

From the material selection chart shown in Fig. 4, Nickel alloys and stainless steel possess better fatigue strength and coefficient of thermal expansion that qualifies both materials as potential material for automotive exhaust system. Fig. 5 is a graphical representation of Thermal conductivity $\left(\mathrm{W} / \mathrm{m} .{ }^{\circ} \mathrm{C}\right)$ against Maximum service temperature $\left({ }^{\circ} \mathrm{C}\right)$. 


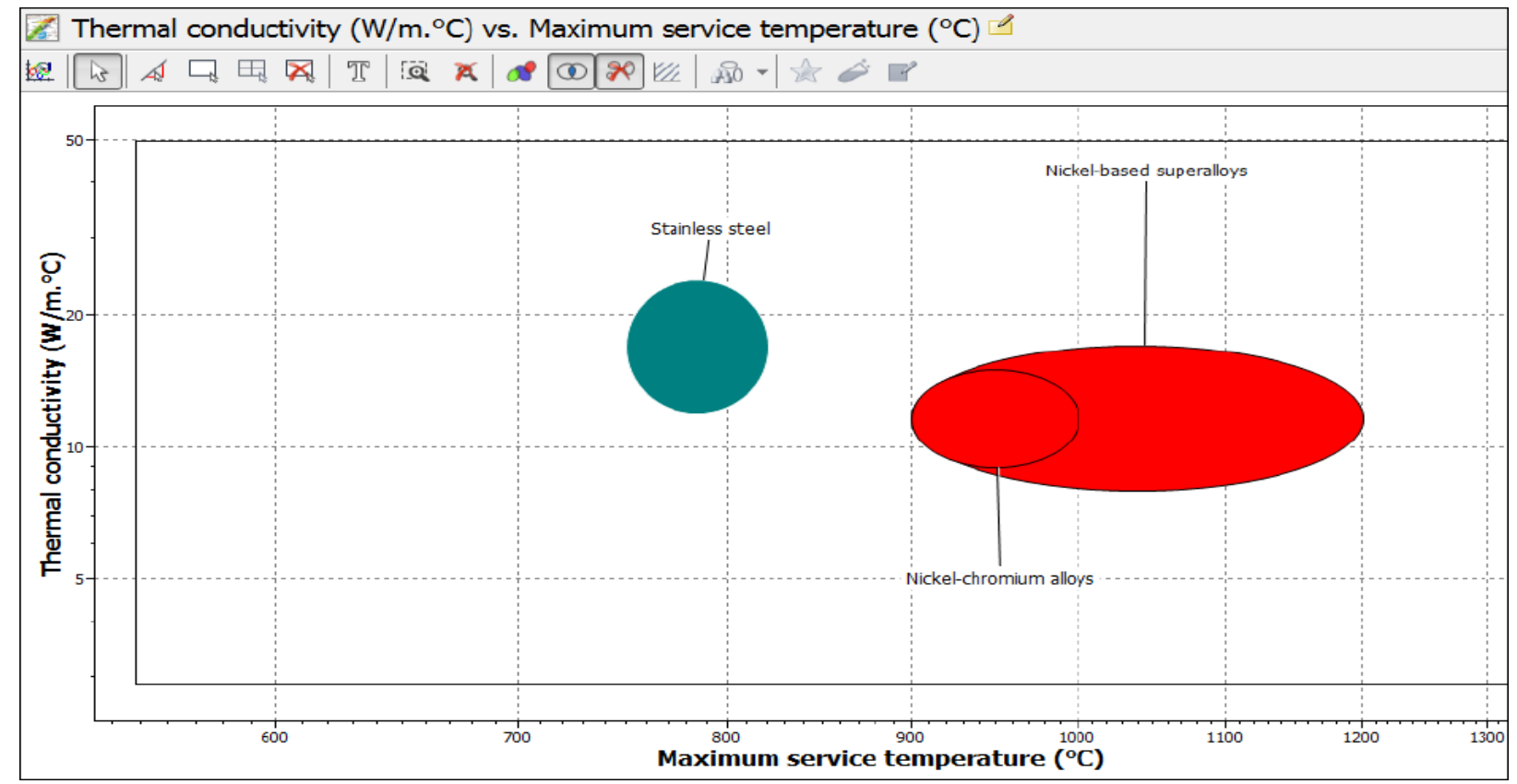

Fig. 5. Graph of Thermal Conductivity $\left(\mathrm{W} / \mathrm{m}^{\circ} \mathrm{C}\right)$ against maximum service temperature $\left({ }^{\circ} \mathrm{C}\right)$.

Fig. 5 presents materials potential materials with high thermal conductivity at the required service temperature. Nickel alloys may operate in a temperature level that outmatches stainless steel, but stainless steel equally have the thermal conductivity required for optimum performance and longevity of exhaust systems.

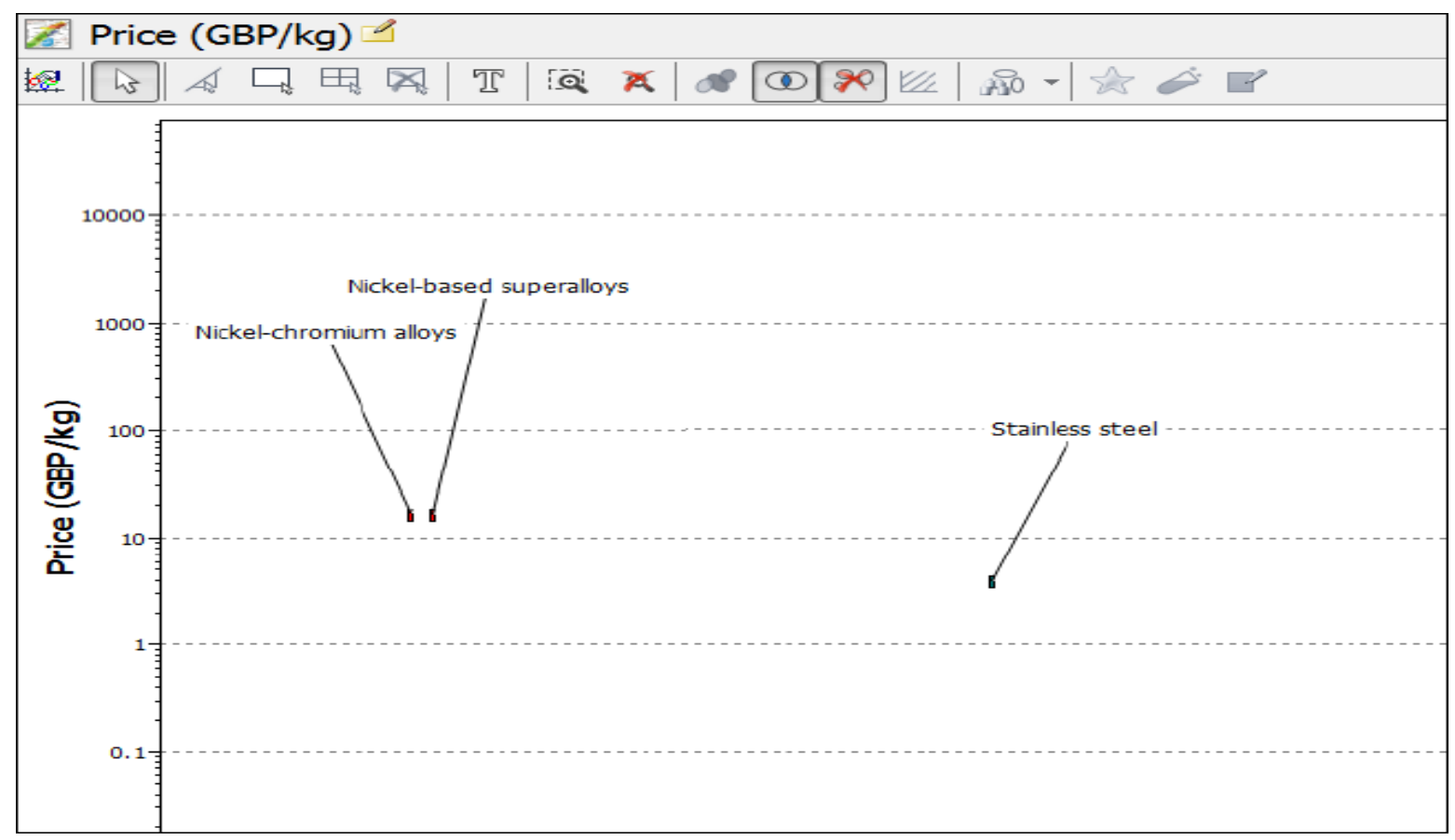

Fig. 6. Graph of Unit Price (GBP/Kg).

As shown in Fig. 6, stainless steel is comparably cheaper than nickel and its alloys. Since cost is one of the primary consideration that determines the feasibility of components production, stainless steel may be a better choice of material for automotive exhaust systems due to its good corrosion resistance property which can improve the material performance and longevity of the product.

\subsection{Muffler Box and Tail Pipe}

The material selection for both the muffler box and tail pipe were done at once as they have similar service conditions and loading properties. Fig. 7 presents the criteria for limits applied in the material selection for the muffler box and tail pipe. 


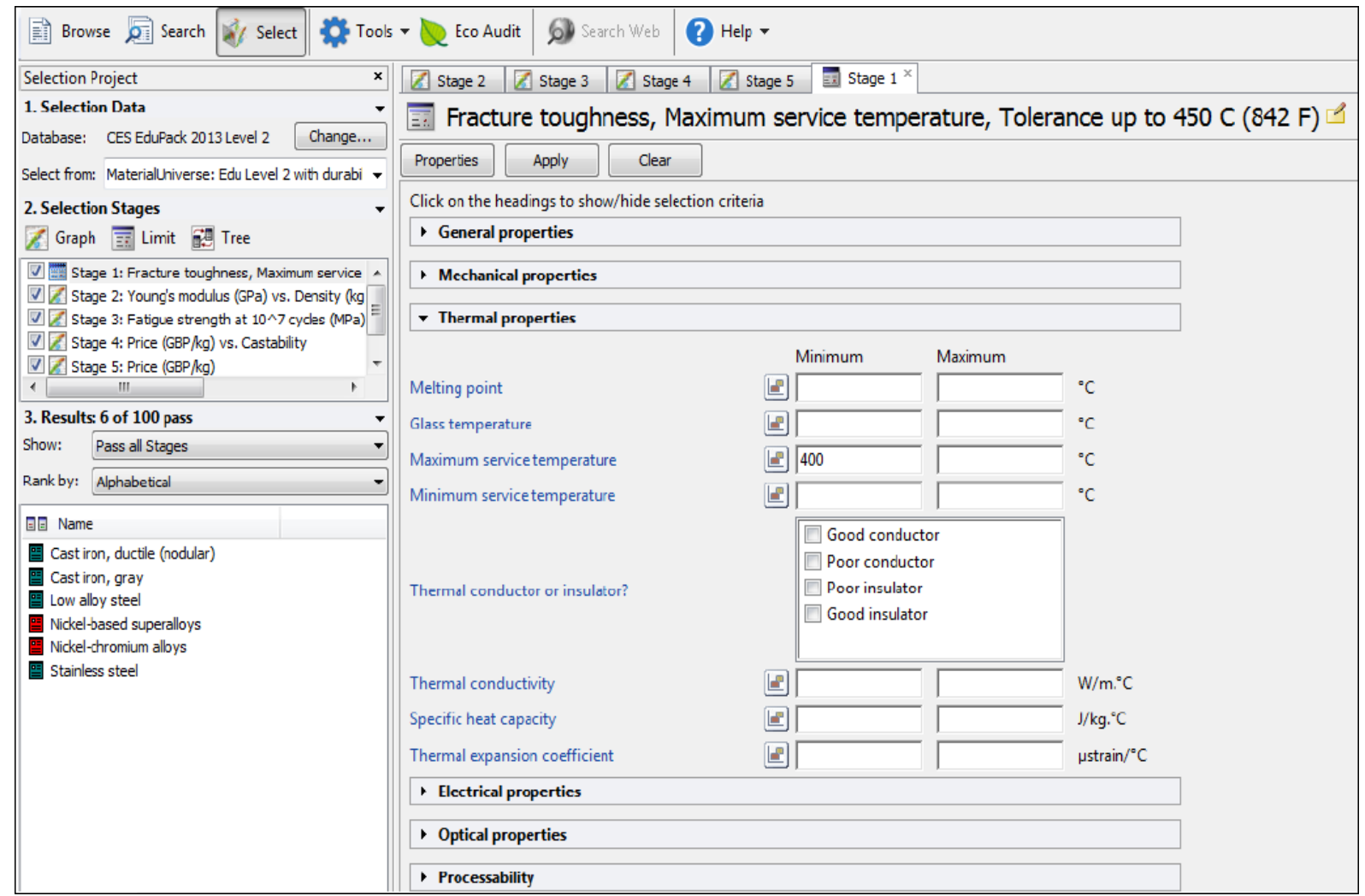

Fig. 7. Chart of Limit Applied in Material Selection for Muffler Box and Tail Pipe.

Once the conditions in Fig. 7. was applied, the following materials passed; gray cast iron, low alloy steel, nickel-based super alloy, nickel-chromium alloy and stainless steel as shown in Fig. 8.

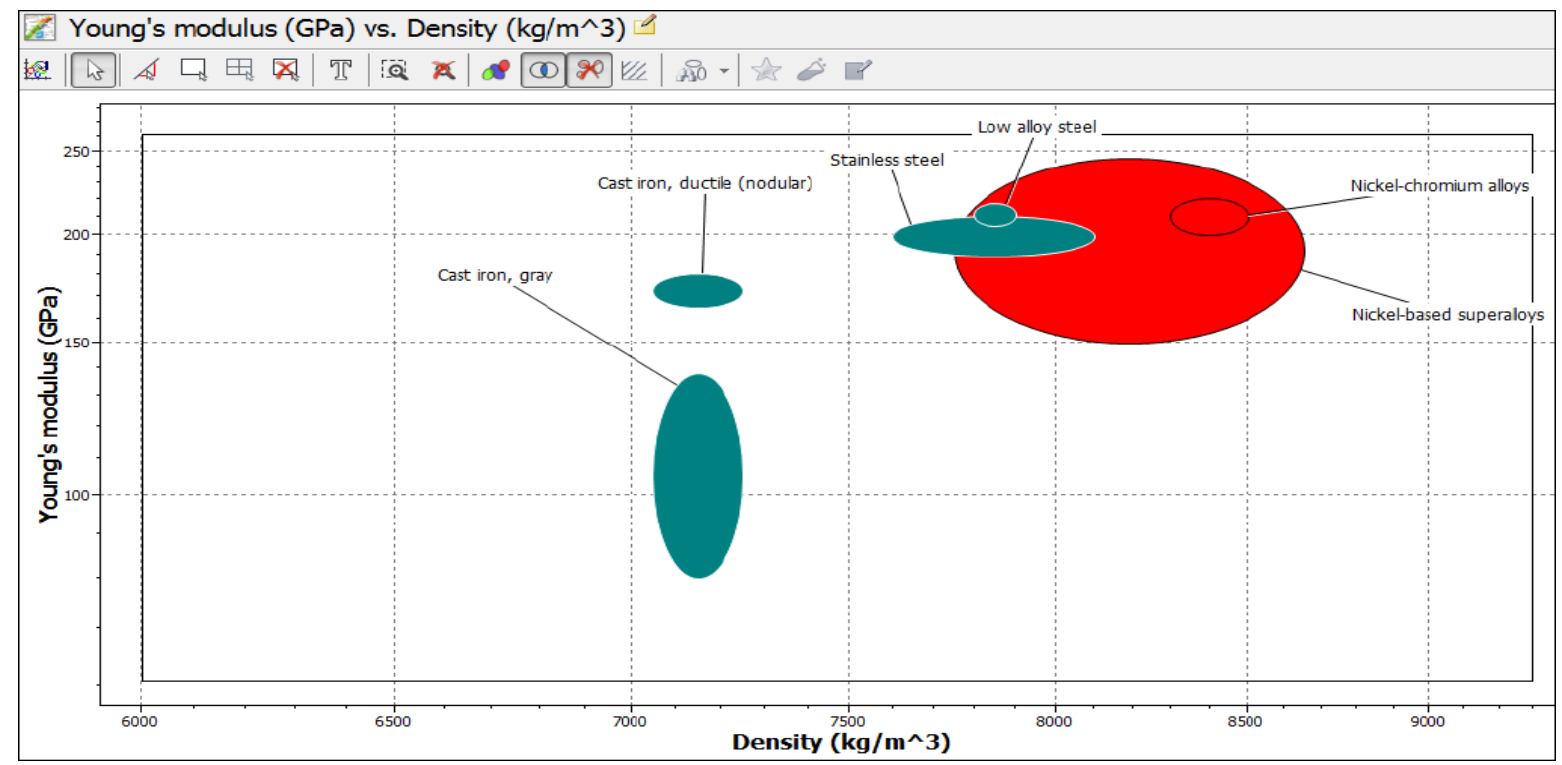

Fig. 8. Graph of Young's modulus $\left(\mathrm{GPa} / \mathrm{kgm}^{-3}\right)$ against specific yield strength $\left(\mathrm{MPa} / \mathrm{kgm}^{-3}\right)$ for Muffler Box and Tail Pipe.

Fig. 8 presents the potential materials for muffler box and tail pipe and these includes such as high carbon steel, stainless steel, cast iron and nickel alloys. Compared to the other three materials cast iron has low toughness and does not possess the strength needed to withstand the adverse conditions the muffler box and tail pipe is exposed to. Nickel alloys has the required strength but its density is relatively high for this application. Stainless steel and low carbon steel possess the required strength and stiffness to withstand vibration, but stainless steel is costlier and has better corrosion resistant property than low carbon steel. Fig. 9 shows a graph of fatigue strength at $10^{\wedge} 7$ Density $\left(\mathrm{kgm}^{-3}\right)$ against thermal expansion coefficient $\left(\mu \operatorname{strain} /{ }^{\circ} \mathrm{C}\right)$. 


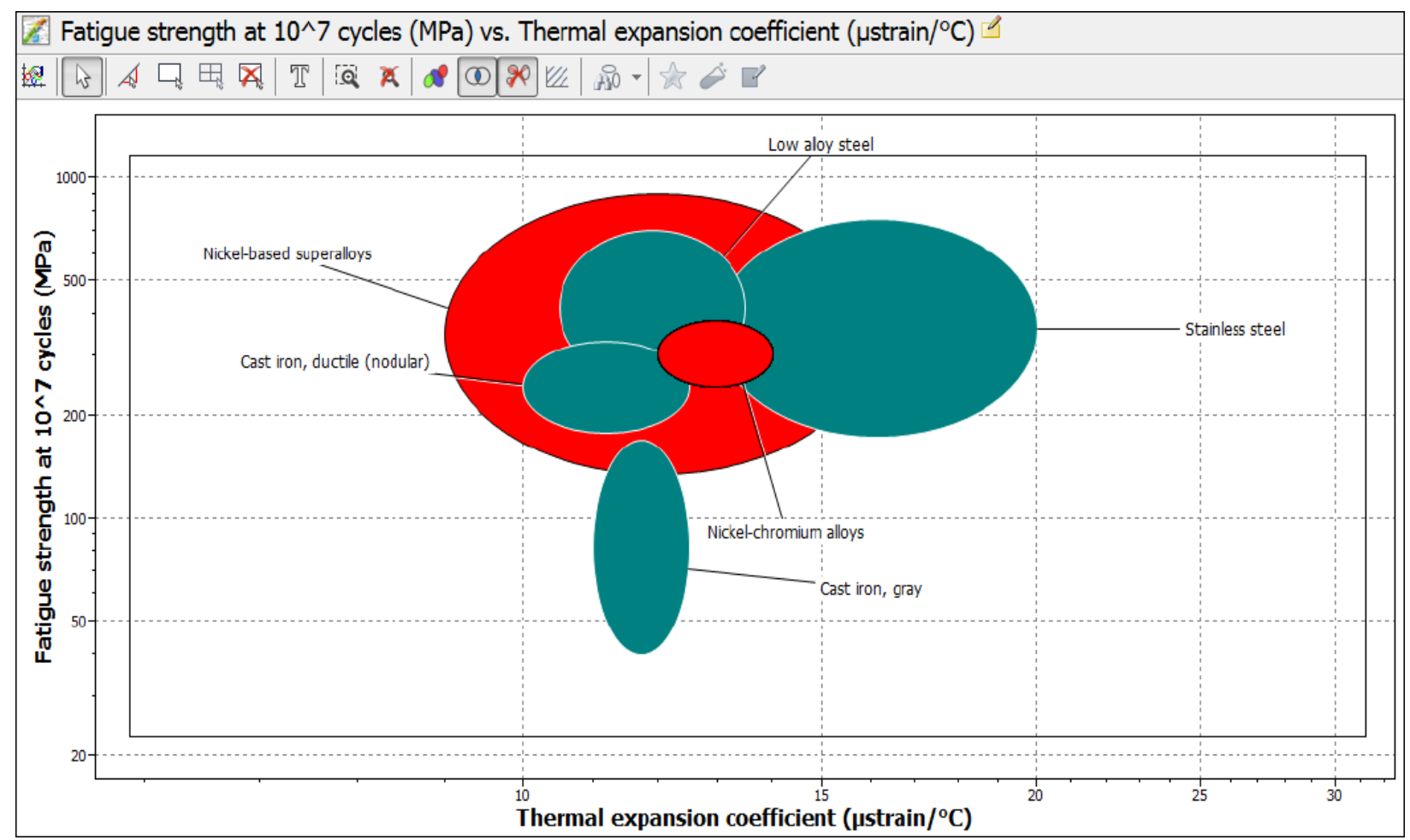

Fig. 9. Graph of Fatigue strength at $10^{\wedge} 7$ Density $\left(\mathrm{kgm}^{-3}\right)$ against Thermal Expansion Coefficient $\left(\mu \mathrm{strain} /{ }^{\circ} \mathrm{C}\right)$.

Nickel alloys can withstand relatively high temperature than other materials shown in Fig. 9. Stainless steel can also be a better material that can suit muffler box and tail pipe in automotive exhaust system application. However in real automotive applications, cast iron also possesses good coefficient of thermal expansion that can equally perform suitably as potential automotive exhaust material. Fig. 10 shows a graph of thermal conductivity $\left(\mathrm{W} / \mathrm{m}^{\circ} \mathrm{C}\right)$ against thermal expansion coefficient $\left(\mu\right.$ strain $\left./{ }^{\circ} \mathrm{C}\right)$.

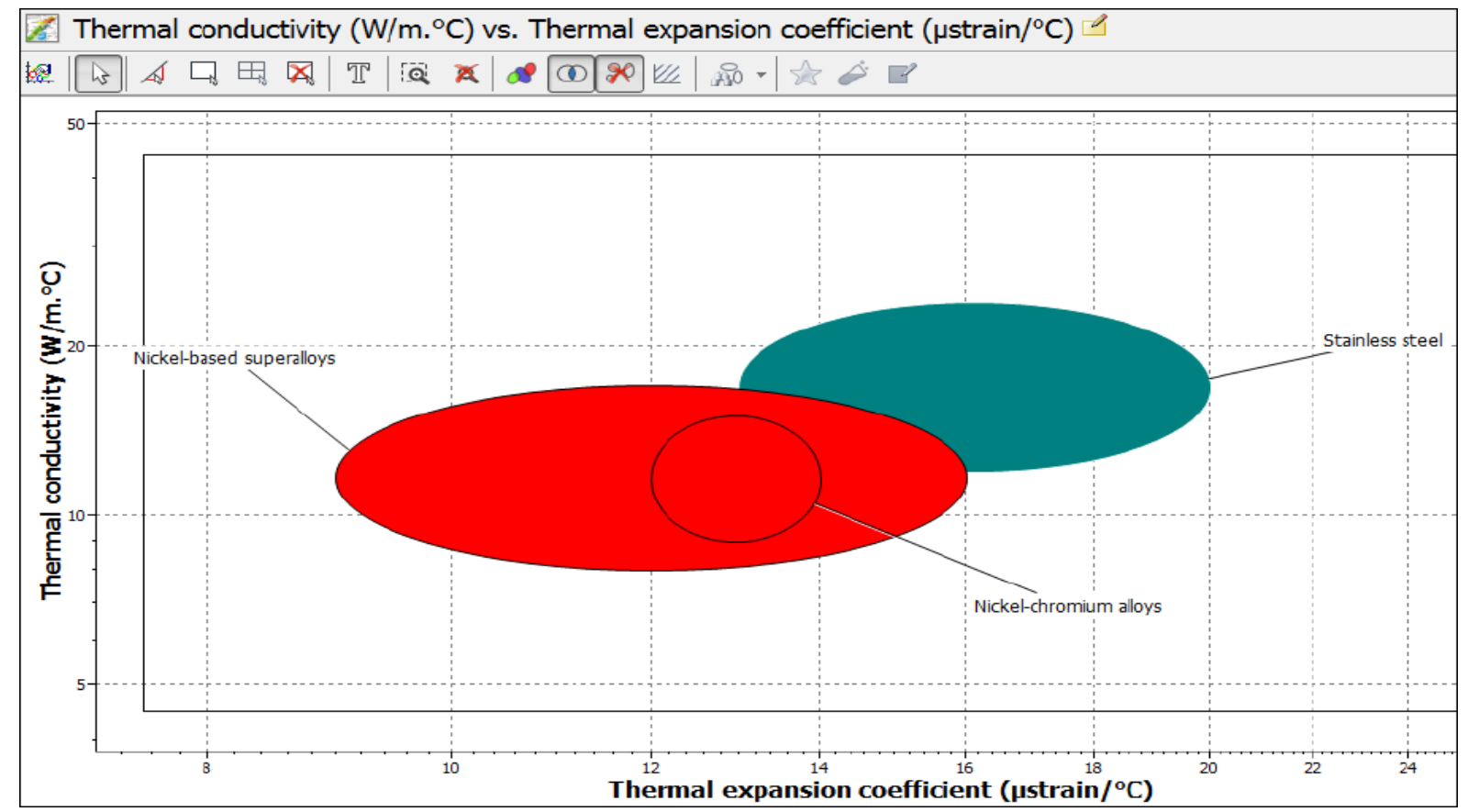

Fig. 10. Graph of Thermal conductivity $\left(\mathrm{W} / \mathrm{m}^{\circ} \mathrm{C}\right)$ against thermal expansion coefficient $\left(\mu \mathrm{strain} /{ }^{\circ} \mathrm{C}\right)$.

As shown in Fig. 10, both materials can withstand the high temperature condition needed for this application. Fig. 11 shows the graph of price for different materials suitable for muffler Box and tail pipe of an automotive exhaust system. 


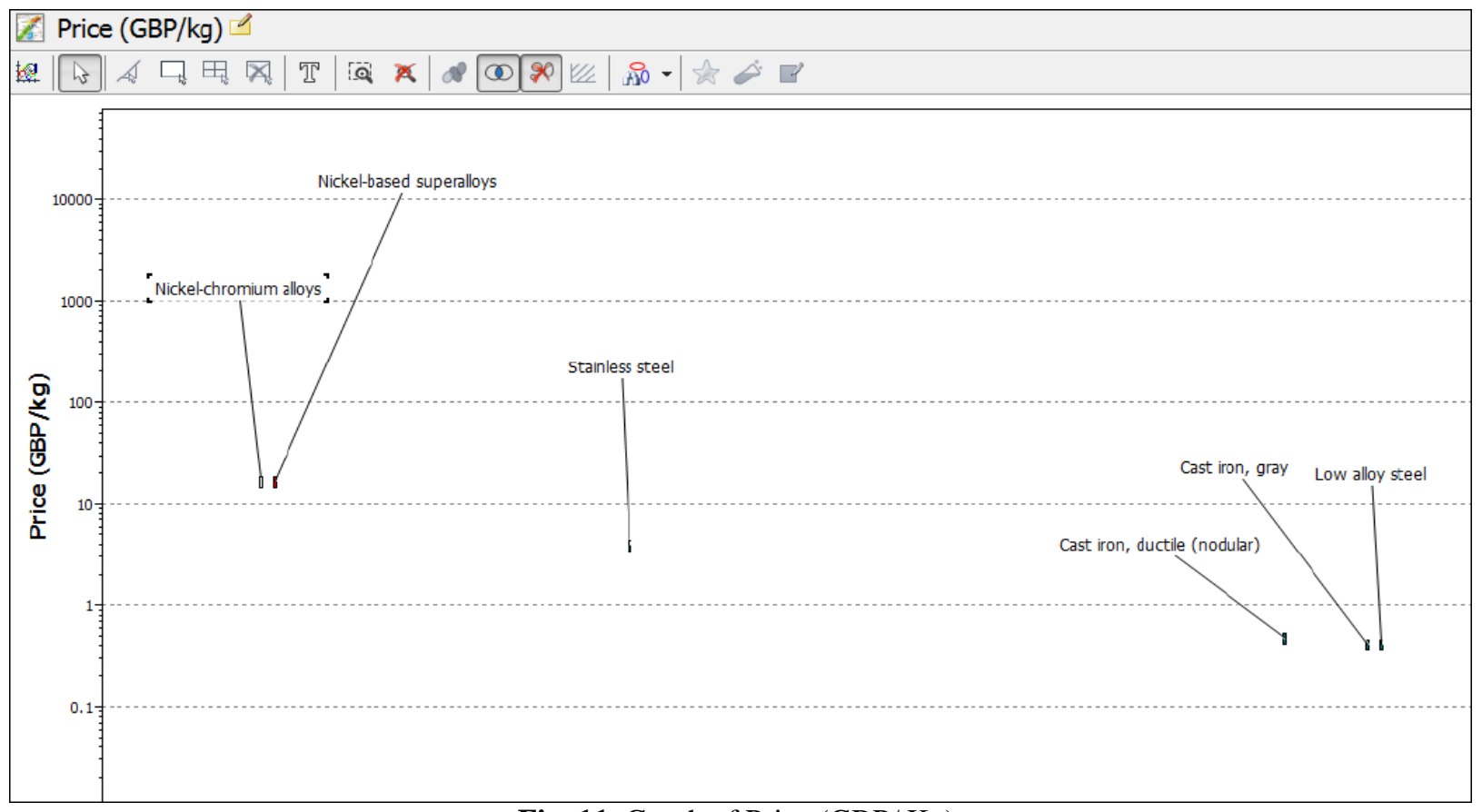

Fig. 11. Graph of Price (GBP/ Kg).

From the graph shown in Fig. 11, cast iron is obviously cheaper than stainless steel, nickel alloys and low alloy steel whereas, stainless steel is comparably more expensive than low alloy steel. However, nickel alloy is relatively more expensive than all the materials in Fig. 11, considered for muffler box and tail pipe of an automotive exhaust system.

\section{Discussion}

Fundamentally, a study of the different parts of the automobile with respect to the exhaust system reveals that it is exposed to various chemical and physical environments that must be accounted for by the choice of material, as well as the design. The position of the exhaust system exposes its parts to frequent vibrations and knockings that require the materials used in processing the parts to be hard as well as flexible. Additionally, the chemical composition of the exhaustive gases brings about the probability of reactions and corrosion between the parts, for example, condensate corrosion and salt corrosion. While starting a car engine in the cold conditions, exhaust system remains at ambient temperature. Condensed moisture content in the exhaust gases accumulates on the muffler and after-treatment system as well as the walls of the tubes. This phenomenon is known as condensate corrosion, and the condensate is sometimes composed of certain compounds such as $\mathrm{CO}_{3}{ }^{2-}, \mathrm{NH}_{4}{ }^{+}, \mathrm{SO}_{4}{ }^{2-}$, $\mathrm{NO}_{3}{ }^{-}, \mathrm{Cl}^{-}$and organic compounds [8]. Also, alloys used in manufacturing exhaust components usually undergo instances where high temperature exposure takes place after the alloys must have been exposed to acidic substances such as road-defrosting salt. This phenomenon is known as salt corrosion, in which the defrosted salt contends halides such as chlorides which can be very aggressive on stainless steel materials, and can act as flux agent that removes the protective oxide layer over time.
In the material selection process shown in Fig. 2-11, stainless steel seems to be a more suitable material for most exhaust system components considered in this paper due to its high corrosion resistant property, stiffness, resistant to high temperature above $400-1000^{\circ} \mathrm{C}$ working condition of typical automotive exhaust system. Also, the exhaust gases can condense and stick on the interior surface of the manifold. This is also one of the reasons why stemless steel is chosen for this application because it prevents condensation of exhaust gases onto its surfaces [9]. Considering the various types of stainless steel materials available, the two most importantly applicable stainless steel materials on automotive exhaust systems are the Ferritic stainless steel, and Austenitic stainless steel.

In addition to chromium and carbon, austenitic stainless steels generally contain nickel between 6 and 35\%. The role of nickel is to stabilize austenite phase, improves mechanical properties fabrication and welding characteristics. Addition of nickel to steel can result in movement of the eutectoid point to the left and also increase the critical range of temperatures. Chromium is usually combined with nickel to achieve required ductility and toughness offered by nickel and the hardness and wear resistance provided by chromium. Sufficient addition of carbon to austenitic grades than ferritic grades can significantly increase the material strength at high temperatures. However, the application of austenitic stainless steels in exhaust system manufacturing attracts considerably higher as a result of the high percentage of nickel content, thus limiting it to applications where a suitable ferritic stainless steel is not available for use.

The application of austenitic stainless steel in automotive exhaust systems offer a refined surface finishing and are usually applicable to higher priced luxury cars and a more demanding applications. 
One of the lower cost austenitic stainless steel often considered for automotive exhaust application is the type 304 , but residual stresses in the material and its exposure to road salt makes this material grade highly susceptible to stress corrosion cracking (SCC) as well as intergranular corrosion if welded as a result of its relatively low nickel content. Compared to Type 304 alloys, austenitic stainless steels such as Type 316 alloys exhibits high resistance to material defects such as stress corrosion cracking and corrosion attack, and are sometimes considered as a better automotive exhaust material due to its higher nickel contents. Type 316L alloys also offer better resistance to intergranular corrosion defect over Type 316 but at the expense of some loss of strength, whereas, Type 316Ti offers almost the same strength as Type 316 alloys and also improved resistance to intergranular corrosion. Moreover, the Type 316 alloys tend to corrode rapidly when exposed to high temperatures and are not usually recommended for applications with temperature exceeding approximately $650^{\circ} \mathrm{C}$.

However, the quantity of ferrite and austenite phases in a steel can be controlled through the percentage concentrations of nickel and chromium [1]. Ferritic stainless steel contains about $30 \%$ chromium in composition and less than $0.12 \%$ carbon and traces of nickel. Although the low carbon percentage reduces high temperature strength, this may not be too much of a concern in many exhaust system applications. Nickel is soluble in ferrite phases and does not form carbides or oxides, whereas, the addition of chromium to steels can result in the formation of variety of very hard carbides of chromium, yet the resulting steel material remains more ductile compared to steel of similar manufactured by simply increasing the percentage composition of carbon. Addition of chromium can also refine the material grain structure, with improved degrees of toughness and hardness. Moreover, it can also increase the critical range of temperatures by moving the eutectoid point to the left. The resultant moderately ductile, excellent resistance to corrosion attack and relatively low cost requirement have made the Ferritic stainless steel a wellknown and widely used material for exhaust systems. A commonly used stainless steel grade such as Type 409 developed in the early1960's for mufflers is a chromium ferritic stainless steel with over $11 \%$ chromium content stabilized with titanium. Higher chromium steels are commonly used nowadays because they offer greater oxidation and corrosion resistance. While 409 served as a good automotive exhaust material, more demanding applications generally require the use of ferritic grades such as 439 which can offer adequate oxidation and corrosion resistance at higher temperatures [4]. Thin double wall pipes in recent times are becoming common for automotive exhaust application, with austenitic stainless steel applicable at the inner pipe in some designs.

Materials generally used for manufacturing exhaust pipes, mufflers as well as other parts of exhaust system comprises ferrous alloys. Aluminium alloys in some cases are also used as a coating on ferrous alloys to provide more resistance corrosion effect. Furthermore, nonferrous nickel and titanium alloys are sometimes applicable in exhaust system parts, particularly when very high performance is required. Ceramics have also had limited application in components of exhaust system to adequately benefit from its insulating properties. Ferrous alloys are primarily dependent on iron-carbon alloys such as stainless steel, carbon steel, alloy steels, cast iron etc. and their performance when used as material for exhaust systems depends on alloying elements are added for the following reasons [16];

i. To provide solid solution strengthening of ferrite,

ii. To cause alloy carbides precipitation instead of cementite $\mathrm{Fe}_{3} \mathrm{C}$,

iii. To improve material resistance against corrosion attack and other unique reasons.

Material choices for exhaust system is driven by several factors such as performance, cost, durability and reliability, warranty requirements and legislated and customer satisfaction. Mild carbon steel has been the choice of material for producing exhaust system components for several decades, due to the fact that the application of iron oxide served as coating on the exhaust system that to some extent protected it from atmospheric corrosion. Generally, it tends to exhibits poor corrosion resistance when exposed to salt on the road surface and condensate from the exhaust system. Consequently, exhaust systems manufactured from Mild carbon steel possessed very short service life when exposed to various environmental conditions by vehicles designed with such exhaust material. The effect of corrosion attack on carbon steel can minimised by means of using a hot dipped aluminium coating generally known as aluminized steel [7].

One of the most widely used ferrous alloy alloying element is chromium, which sufficient addition of it results in stainless steel. If the temperature of stainless steel is raised, the chromium content forms a protective chromium oxide layer that prolongs oxidation rate. The minimum quantity of chromium required to passivate the surface and to classify a given material as stainless steel is about $10.5 \%$. As long as the oxide layer constantly remains stable, the metal substrate is remains protected against corrosion attack on the material which in turn prolongs the component service life. More preference was given to stainless steel in the mid1990 s as the principal material for components of exhaust systems downstream (than plain carbon and low alloy steels) such as the exhaust manifold or turbocharger. In recent times, this transition has taken precedence due to customer's demands for extended warranties and emission tax. Over the years, technologies to meet highly stringent emission polices has raised exhaust temperatures which in turn has made the task of meeting strength and performance requirements very challenging. In the early $21^{\text {st }}$ century, requirements including several alloying elements used in stainless steel have experienced an extensive rate in price fluctuations. As a result of this, stainless steel manufacturers have included an adjustable alloy surcharge to account for these price variations. Many manufactures have invested on research studies to reduce the sensitivity of the finished product's price to these alloy surcharges [10]. 


\section{Conclusion}

In conclusion, material selection is a factor of numerous aspects of a component's design. The choice of the material is governed by very many factors as shown in the study above. One interesting factor is that the more challenges a component is exposed to in its in-service life, the higher requirements to improve the material performance and the wider the research needed to understand the challenges bedevilling the component prior to carrying out the material selection. High temperature and corrosion attack were spotted at as the primary defects that hampers the service life of an automotive exhaust system, and stainless steel (Ferritic stainless steel and Austenitic stainless steel) was selected as a choice of material suitable enough to withstand this challenges, and this is not too different from the conventional exhaust materials.

\section{Acknowledgement}

The authors of this manuscript would like to express their gratitude to Coventry University for providing the tools used in achieving the objectives of this paper.

\section{References}

[1] N. Arlt, Korrosions-und hitzebeständige Stahle in Abgassystemen. CTI Exhaust Materials Forum 2122.11.2007, Frankfurt, Germany, 2007.

[2] D. Askeland and P. Pradeep, The Science and Engineering of Materials. Thomson Engineering, 2005.

[3] M. Ashby, H. Shercliff, and D. Cebon, Materials Engineering, Science, Processing and Design. USA, Butterworth-Heinemann, 2007.

[4] ATI, Stainless Steels Type 439/AL 439 HP. ATI Allegheny Ludlum Corporation Blue Sheet Technical Data, Pittsburgh, Pennsylvania, USA, 1999.

[5] W. Callister, Materials Science and Engineering. New York, John Wiley \& Sons, 2007.
[6] D. Gaskel, Introduction to the Thermodynamics of Materials. Taylor and Francis Publishing London SW1P 1WG, 1995.

[7] M. S. Chattha, J. Perry, R. L. Goss, C. R. Peters, H. S. Gandhi, Corrosion of aluminized low carbon steel exhaust system in vehicles equipped with three-way catalytic converters and development of a protective polymeric coating, Ind. Eng. Chem. Res., 29 (7), 14381442, 1990.

[8] P. Gumpel and C. Hoffmann, Corrosion resistance of stainless steels to wet condensates in automotive exhaust systems. Proceedings of the 6th European Stainless Steel Conference, Helsinki, 2008.

[9] D. Green, R. Hannink and M. Swain, Transformation Toughening of Ceramics. Boca Raton: CRC Press, 1989.

[10] Y. Inoue and M. Kikuchi, Present and future trends of stainless steel for automotive exhaust system", Nippon Steel Technical Report No. 88, 2003.

[11] A. E. Ikpe, I. Owunna, P. O. Ebunilo and E. E. Ikpe, Material Selection for High Pressure (HP) Turbine Blade of Conventional Turbojet Engines. American Journal of Mechanical and Industrial Engineering 1 (1), 1-9, 2016.

[12] P. Lewis, K. Reynolds and C. Gagg, Forensic Materials Engineering: Case Studies. Boca Raton: CRC Press, 2003.

[13] F. Mathews and R. Rawlings, Composite Materials: Engineering and Science. . Boca Raton: CRC Press, 1999.

[14] Precision Automobile, exhaust system [online] available

http://www.precisionautosales.com/exhaust.php, 2000.

[15] J. Shackelford, Material Science for Engineers. Prentice Hall: Upper Saddle River, 2000.

[16] K. Zimmermann, Lightweight design in exhaust systems using tailored products. 9th International CTI Forum Exhaust Systems, January 26, 2011, Stuttgart, Germany, 2011. 